\title{
Profiles and Developmental Goals in Different Families of Rio de Janeiro ${ }^{1}$
}

\author{
Luciana Fontes Pessôa ${ }^{2}$, Dandara Ramos ${ }^{3}$, Lenise Vivas² \\ ${ }^{2}$ Pontificia Universidade Católica do Rio de Janeiro, Rio de Janeiro-RJ, Brazil \\ ${ }^{3}$ Fiocruz Bahia, Salvador-BA, Brazil
}

\begin{abstract}
The study of child development goals has been of interest in psychology for decades, however, little is known about the goals of non-nuclear families. The objective of this study was to analyze inter and intragroup differences in the profiles of autonomy, interdependence and related autonomy of couples in different family arrangements in the city of Rio de Janeiro, as well as to investigate the association of these profiles with the development goals they have for their families' children. Fathers and mothers of children up to two years old were interviewed in 50 families (10 single-parent, 20 reconstituted and 20 nuclear). The results indicated an association between the autonomy and valorization of heteronomy goals in reconstituted families and higher interdependence scores in non-nuclear families. It is concluded that the family configuration can influence the relationship between autonomy and goals, and that the autonomy trajectories vary between family arrangements.
\end{abstract}

Keywords: socialization, family structure, developmental psychology, autonomy, childrearing practices

\section{Perfis e Metas de Desenvolvimento em Diferentes Arranjos Familiares do Rio de Janeiro}

\begin{abstract}
Resumo: $\mathrm{O}$ estudo das metas de desenvolvimento infantil tem sido alvo de interesse na psicologia há décadas, no entanto, pouco se sabe sobre as metas de famílias não nucleares. O objetivo desse estudo foi analisar diferenças inter e intragrupos nos perfis de autonomia, interdependência e autonomia relacionada de casais em diferentes arranjos familiares na cidade do Rio de Janeiro, assim como investigar a associação destes perfis com as metas de desenvolvimento que estes possuem para os seus filhos. Foram entrevistados pais e mães de crianças de até dois anos em 50 famílias (10 monoparentais, 20 reconstituídas e 20 nucleares). Os resultados indicaram associação entre autonomia e valorização de metas de heteronomia em famílias reconstituídas e os escores mais elevados de interdependência em famílias não nucleares. Conclui-se que a configuração familiar pode influenciar a relação entre autonomia e metas, e que as trajetórias de autonomia variam entre os arranjos familiares.
\end{abstract}

Palavras-chave: socialização, estrutura familiar, psicologia do desenvolvimento, autonomia, práticas de criação infantil

\section{Perfiles y Metas de Desarrollo en Diferentes Tipos de Familia de Rio de Janeiro}

Resumen: El estudio de las metas de desarrollo infantil ha sido objeto de interés en la psicología desde hace décadas, sin embargo, se sabe poco sobre las metas de familias no nucleares. El objetivo de este estudio fue analizar diferencias inter e intragrupos en los perfiles de autonomía, interdependencia y autonomía relacionada de parejas en diferentes tipos familiares en la ciudad de Río de Janeiro, así como investigar la asociación de estos perfiles con las metas de desarrollo que poseen para sus niños. Se entrevistaron a padres y madres de niños de hasta dos años en 50 familias (10 monoparentales, 20 reconstituidas y 20 nucleares). Los resultados indicaron asociación entre autonomía y valorización de metas de heteronomía en familias reconstituidas y las puntuaciones más elevados de interdependencia en familias no nucleares. Se concluye que la configuración familiar puede influenciar en la relación entre autonomía y metas, y que las trayectorias de autonomía varían entre los arreglos familiares.

Palabras clave: socialización, estructura familiar, psicología del desarrollo, autonomía, prácticas de creación infantil

Psychology and anthropology have, for decades, tried to establish the principle that the child care structure, adopted practices, and beliefs and values governing these practices

${ }^{1}$ Support: This study was funded by Carlos Chagas Filho Foundation (FAPERJ), grant APQ1 E.26/211.444/2015.

Correspondence address: Luciana Fontes Pessôa. Pontifícia Universidade Católica do Rio de Janeiro. Psicologia. Rua Marquês de São Vicente 225, Rio de Janeiro-RJ, Brazil. CEP 22.451-900. E-mail: pessoalf@gmail.com vary throughout human history and are shaped by culture. Thus, there are differences between human cultural groups, made up of people who share a set of artifacts, practices, and belief systems (Kobarg, Sachetti, \& Vieira, 2006).

The focus on belief systems and parental practices had a considerable impact on psychology from the studies by Margaret Mead and John and Beatrice Whiting, who collected evidence from various cultural groups on the organization of care and the belief systems that guided these actions. Since 
then, the emphasis on the cultural determination of parental belief systems and, consequently, on the adopted care practices has produced an impressive body of knowledge about cultural variability, from the 1970s.

Harkness and Super (2006) worked with the concept of cultural models, defined as shared understandings that surround experiences, providing interpretations, inferences, and objectives for actions. These cultural models are organized into interdependent categories and are, therefore, termed parental ethno-theories. They can be defined as cultural models/examples or a set of the parents' ideas on how to understand the personality and intelligence of the child, which have motivational properties that act as goals and interpretations of the reality for parents. The ethnotheories are implied in the experience of daily life that parents have with their own children and result from their interaction history and culture accumulated in the community or reference group.

For Harkness and Super (2006), the origins of parental ethno-theories are in the socio-economic structure of the parents' lives. However, the authors argue that, on this structure, the parents make the decisions on how to socialize their child individually. In this sense, the parental ethnotheories are expressed in different social and physical environments, which parents select and organize for their child. An example can be verified in the study by Miller and Harwood (2001), with Anglo-American and Puerto Rican mothers from the middle class. The authors identified correlation between socialization goals in the long run with the type and frequency of social contact that the mothers built for their children. American mothers put more emphasis on more individualistic goals, related to self-improvement, while the Puerto Rican mothers, relatively, emphasized more qualities of good behavior. The authors also noticed that the children's daily life environment and the time they spent on different activities presented many aspects from the social ecology of infancy and are related to the beliefs and parental practices of care of their caregivers, in the specific case of the mentioned study, the mothers. The emphasis given to the investigation of parental beliefs is justified by the fact that the parental ethno-theories can be considered an important force in the adoption of parental care practices and in the organization of the daily life of the child and the family.

The search for regularities in the research on parental beliefs and culture was strongly directed to the individualism/ collectivism debate, since the 1980s (Kağitçibasi, 2012). The attempt to explain cultural variations from this construct has been of great attraction among anthropologists, sociologists, and psychologists. Kağitçibasi (2012) analyzes the literature on the theme and summarizes the main accumulated evidence favoring the collectivism/individualism construct. The author emphasizes systematic variations found among cultures regarding this dimension. She points out evidence that the individuals demonstrate values and behaviors more or less individualistic or collectivist according with the society in which they live and that individual or group variations within the same culture can be reliably linked to differences of groups within the same society. It is important, however, to emphasize that social standards of individualism and collectivism are not directly attributable to the individual level. There is a gradient of variation regarding the trajectories of development that can be traced in collectivist or individualist cultures and these trajectories may return to autonomy, interdependence, or related independence.

\section{Socialization Trajectories in which autonomy and interdependence are built}

Along the development, the tasks involved in raising children are organized around different socialization goals, of independence (success, self-realization, happiness) or interdependence (harmonious relationship with family, good behavior, meeting of social norms, etc.; Seidlde-Moura, 2012). In industrialized society this would correspond to the valuation of respective standards of individualism or collectivism. These goals are related to implied ethno-theories, which are belief systems regarding ideal children and adults and what needs to be done for them to develop in this direction. These ethno-theories are shared and traded between community members and result in care practices that will influence the direction taken by each activity performed.

Thus, two development paths are proposed. The interdependent path consists on the adaptive answer, in evolutionary terms, to the conditions of small communities where a subsistence economy predominates. In them, tradition is valued and changes in belief systems are slower. Ethno-theories are transmitted mainly vertically, between generations, and with it the historical continuity is maximized. In the independent path, in contrast, the adaptation is to urban communities that are large, anonymous, and with an economy of trade and services. Innovation is valued and the changes are fast. With that, the ideas, which are anchored on the public discourse through the media and the opinion of experts, change between generations and are negotiated horizontally, within a single generation (Keller, 2007, 2012).

Keller (2012) hypothesis on and has been investigating two main trajectories in the development of the self. For the author, the early social experiences, organized by beliefs and practices, both individual and shared, of the caregivers constitute the bases of these distinct trajectories. She proposes that, from these different trajectories (of independence or interdependence), the development of the self is directed to various directions: independent, interdependent, or autonomous-related self, which are derived from distinguished models of contact/care of mothers and fathers regarding their children.

In the first, independence is privileged, including autonomy and separation, characterizing a type of distal relationship, which emphasizes face-to-face exchanges and stimulation by objects, being considered an interaction standard characteristic of Western middle-class, urban, and educated families. The second model, interdependent, focuses on heteronomy and relationship, characterizing 
a proximal relationship type. It emphasizes contact and body stimulation, being considered characteristic of rural families with low socio-economic and educational levels. In the third, autonomous-related, both autonomy and relationship are prioritized. This model would be an intermediate form between the first and the second, being considered characteristic of urban, highlyeducated, middle-class families, who live in traditionally interdependent societies.

\section{Autonomy and Interdependence in Families from Different Contexts}

In a national study, with a group of mothers from Rio de Janeiro, aspects of the cultural models of a group of 200 young first-time mothers with children aged less than 44 months were investigated (Seidl-de-Moura et al., 2009). The participants responded to the Socialization Goals Interview (SGI) and to an adapted version of an inventory of beliefs about care practices (Suizzo, 2002) translated and adapted (Martins, et al., 2010). The data were analyzed in terms of the SGI categories, scores in the inventory of practices, subcategories of self-realization (feeling good regarding oneself - psychological well-being, personal and economic potentials, and psychological independence), and good behavior (avoid illicit behavior, personal integrity, and religious values). The results showed that the mothers from Rio de Janeiro highlighted the relevance of an autonomy model for their children, but also believed in the importance of the relationship with others.

This model also includes a concern with potential stimulation of the children in different areas and how their children are presented in public. This model of autonomy has specific characteristics and is differentiated in some aspects compared to what can be observed in other cultures. For example, German mothers from the study by Citlak, Leyendecker, Schölmerich, Driessen, and Harwood (2008) value more self-control than self-realization. In general, this group of mothers from Rio de Janeiro desire success for their children, especially in the professional and economic aspects. However, they do not want their children to be successful regardless of the way employed to achieve their goal, as can be seen in their answers in the subcategories of good behavior. The highest mean was in the subcategory personal integrity and religious values, which is related to standards such as being hardworking and honest. In addition, the mothers want their children to be successful and achieve their potential, but through hard work and with honesty. An important factor was the effect of the educational level of the mothers in their beliefs regarding autonomy. Mothers with higher educational levels give more importance to the psychological well-being, while mothers with lower educational levels valued more the personal and economic development of their children.

Vieira et al. (2010) compared 600 women from 12 cities, of six Brazilian states (Pará, Bahia, Espírito Santo, Rio de Janeiro, São Paulo, and Santa Catarina).
Two groups were compared: one of mothers who live in the states' capitals and the other of mothers who lived in small towns with less than 24,000 inhabitants. The dimensions autonomy and interdependence were analyzed regarding the mothers' beliefs concerning the socialization of their children, their practices, and degree of allocentrism. Although the mothers from both contexts valued autonomy, the ones who resided in small towns considered the relational dimension as more important. Mothers from the capitals valued equally the dimensions of autonomy and interdependence in their socialization goals for their children as well as in their care practices. The mothers from the small cities showed a higher score of allocentrism (link with their families of origin) than the mothers from the capitals. Although expected, the educational level in the variables considered and in this group of mothers did not show any significant effect.

More recently, Lordelo, Roethle, and Mochizuki (2012) investigated the socialization goals of Brazilian and Norwegian mothers, comparing the order of evocation of descriptors related to individualism and collectivism when answering the question: "What qualities would you want for your child as an adult?". In the analysis of the results, the authors identified a common basis in the mothers' evocations in the two samples, sharing as desired qualities for the children the socialization goals related to economic and social success in adult life. These results suggest the vital character of these ideals, shared in urban, industrial, or post-industrial societies.

With the purpose of identifying the experiences of mothers and fathers regarding decision-making concerning childrearing in reconstituted families, Ripoll-Núñez, Martínez Arrieta, and Giraldo Gallo (2013) interviewed nine women and three men in Colombia. The results indicated that mothers and fathers prioritized more autonomy in decisions related to the raising of their children and that both partners were involved in the raising and decisions about children's care practices. The valuing of autonomy in the speech of the couples was identified, especially regarding decision making concerning their children. In addition, the authors identified an emphasis on recognition of the importance of respect and obedience to both caretakers, consanguineous or not.

Trying to understand the parenting strategies of mothers from West Africa and Italy, Carra, Lavelli, Keller, and Kärtner (2013) compared the socialization and parental behavior during the interaction of first-time mothers with children aged 3 months old. The relationship between the socialization goals and maternal behavior was investigated in the two groups. The results showed that West African immigrant mothers prioritize the goals that emphasized a hierarchical model and a proximal parental style. Italian mothers, on their turn, emphasized the goals aimed at psychological autonomy and a distal parental style.

Park, Coello, and Lau (2014) analyzed the valuing of socialization goals of Western parents (Australia, England, Canada, and United States) and parents from East Asia (China, Japan, Korea, Taiwan) between 1989 and 2010 and noted that East Asian parents valued independence more, 
while Westerner parents prioritized obedience, altruism, tolerance, and respect as valued qualities in the raising of their children.

All these studies focused on mothers and children aged under six years and used a set of instruments. In addition, they focused on a very specific type of families, usually nuclear, with parents living together and with a majority of first-time mothers. It is considered that these studies should be extended in various ways, among them, considering other familiar settings, for example, single parent and reconstituted; and also, investigating the goals and practices of the main caregivers in these types of family. Thus, we believe that investigate new family settings and not just nuclear families, can contribute to the literature of the area to the extent that the studies seek to compare and verify the impact that family setting can have regarding the trajectories trends prioritized by the caregivers, as well as regarding the socialization goals and practices of their children.

\section{Different Contemporary Family Settings}

The family has been transforming throughout time, accompanied by religious, economic, and socio-cultural changes of the context in which it is inserted. Regarding these changes, it is possible to highlight: demographic changes, especially the greater human longevity; the growing participation of women in the labor market; the divorce and family organizations other than the traditional nuclear family, which were strengthened as a result of this; the advent of birth control, resulting in the control of procreation; and the changes in parenting and gender roles (Cardoso, 2011).

In recent decades, many definitions have been attributed to the contemporary family. Féres-Carneiro and Magalhães (2011) speak of the "complexity of the family with its multiple possibilities of organization" to refer to the multiple contemporary family arrangements, which, for the authors, did not eliminate neither the traditional logic or the modern logic. Nowadays, there is a "coexistence of different models or even with the presence of hybrid family models. There is a permanent renegotiation of positions and the values are continuously reformulated" (Féres-Carneiro \& Magalhães, 2011, p. 118).

Therefore, at the present time, new ways of parenting arise, in which multiple marital arrangements originate new family configurations. Single-parent families are being progressively established, so that the children now live with just one parent. In addition, with the increase in divorce rates, the number of separated, re-married, and rebuilt families are intensified, thus, the children of parents who separate and marry again are now collecting half-brothers and half-sisters. Homoparental families are also being born, characterized by the marital bond of two people of the same sex and socio-affective, showing new trends in the concept of affiliation, formed by a family relationship initiated by social conviviality and, within this coexistence, affection in its positive sphere emerges.
Thus, this study included the different family types, such as: nuclear (families with parents living together), reconstituted (families that include children from previous relationships and current relationship), and single-parent (families in which only one caregiver is responsible for childrearing). We sough to investigate the care goals and practices of those who take the paternal and maternal function, as well as which are the specific trajectories trends, based on autonomy, interdependence, and related autonomy of these caregivers. In short, it is necessary to investigate how the beliefs and valuing of autonomy and/or interdependence reflect in the development goals of these caregivers. Such beliefs, in the literature, have been considered until now without taking into account the dynamics of its constitution and transmission in different non-nuclear family arrangements.

In this empirical study, we intend to identify these beliefs from the prevailing profiles and development goals in three different families settings in the state of Rio de Janeiro. The main research question was: "Does the balance dynamics of autonomy and relationship which we have found in Brazilian studies present itself in families different from the nuclear setting?"

The overall objective of this study was to analyze possible inter and intragroup differences in the profiles of autonomy, interdependence, and related autonomy of couples in different family arrangements in the city of Rio de Janeiro, as well as to investigate the association of these profiles with the development goals parents have for their children. The specific objectives were: (a) describe autonomy, interdependence and related autonomy profiles of mothers and fathers on different family arrangements (nuclear, reconstituted, and single-parent); (b) compare (intra-group) the profiles of fathers $\mathrm{x}$ mothers in nuclear and reconstituted families, as well as compare the profiles of groups among themselves (nuclear x reconstituted x single-parent); and (c) analyze the association of autonomy, interdependence, and related autonomy profiles with the development goals of mothers and fathers of the general sample and in different family arrangements, separately.

\section{Method}

\section{Participants}

Ten families of the single-parent type (20\%), 20 reconstituted families (40\%), and 20 nuclear families (40\%) participated in the research. Among the respondents, 30 were mothers $(60 \%)$ and 20 fathers (40\%), since the single-parent families in the study were composed only by mothers, with children aged up to two years. The children of the sample's participants are mostly boys $(N=30,60 \%)$, with a mean age of 13.3 months $(S D=7.54)$.

\section{Instruments}


Socialization Goals Inventory The Socialization Goals Inventory, developed by Keller et al. (2006) and used in other studies (Keller, 2007; Lamm et al., 2007) consists of a list of ten phrases that indicate goals that parents will try to achieve in the development of their children during their first three years of age. The goals are subdivided in two dimensions: independence/autonomy (items: "develop independence", "develop self-confidence", "develop competitiveness", "develop a sense of self-esteem", and "develop a sense of identity") and interdependence/ relationship (items: "learn to obey the parents", "learn to obey older people", "learn how to cheer up other people", "learn how to take care of other people's well-being", and "learn to control emotions").

In the application of the instrument, we asked the participants to indicate whether they agree or not, on a scale of 1 (do not agree at all) to 5 completely agree), reacting spontaneously, without thinking too much. In the original validation studies, the scale showed good measures of reliability (Cronbach's $\alpha=.93$ for them items independence/ autonomy and $\alpha=.89$ for the items interdependence/ relationship) (Keller, 2007). For the analysis carried out in this study, we considered the subscales of the Socialization Goals Inventory and also the answers of the participants, in one to five scores attributed to the valuing of each of the ten goals, treated as ordinal type dependent variables and used in nonparametric tests of association with the independent variables of each analysis.

Autonomy, Interdependence and Related AutonomyScales The Autonomy, Interdependence, and Related Autonomy scales of Kagiçitbasi were used in the translated version for Portuguese, validated by Seidl-de-Moura, Fioravanti-Bastos, Carvalho, and Ziviani (2013). The set of scales is presented in a single instrument with 27 items, nine for each subscale. Examples of items from each subscale are: "I do not appreciate interference from any person in my life, even if it is someone close to me (autonomy subscale - item 13)"; "I do not share my personal affairs with anyone, even if they are very close (interdependent/relationship subscale - item 15)"; "A person can feel both autonomous and linked to those close to them (related autonomy subscale - item 24)". In its validation to the Brazilian context, the Cronbach's alpha of internal consistency indicated a value of 0.69 to the Autonomous Self scale, 0.67 for the Related Self scale, and 0.73 for the Autonomous-Related Self scale, indicating moderate consistency of the three scales (Seidl-de-Moura, FioravantiBastos et al., 2013).

\section{Procedure}

Data collection. The families were indicated by participants of the research group. In the first contact with the family, the researcher requested the cooperation of the informant, explaining the research's objectives and methods. After agreeing to participate, the researcher gave them the informed consent form, the sociodemographic data sheet, and the instruments that were filled out by the participants randomly, in the place of their convenience and immediately delivered to the researcher. The mean time of completion was 15 minutes.

Data analysis. The variables Socialization Goals (independence/autonomy and interdependence/relationship subscales), Autonomy score, and Interdependence score presented approximately normal distribution (KS test $p>0.05$ ). However, the related autonomy score presented strong asymmetry (Skewness $=-4.4$ ), deviating from the normal distribution (KS test $p<0.05$ ). Therefore, to respect the assumptions of the statistical test for intragroup (comparison of the members of a same family type, e.g. fathers $\mathrm{x}$ mothers of nuclear families, fathers $\mathrm{x}$ mothers of reconstituted families) and intergroup comparison (comparison of the family groups among each other, e.g. fathers and mothers from nuclear families mothers $\mathrm{x}$ fathers and mothers from reconstituted families $\mathrm{x}$ mothers of nuclear families) of the first two variables, ANOVA tests were carried out, while for the third variable the non-parametric Kruskal Wallis test was performed. In the original proposition of the instrument, by Keller et al. (2006), the independence/autonomy and interdependence/ relationship subscales scores did not present any correlation between them. However, in our sample the scores showed significant correlation $(r=0.62 ; p<0.05)$. For this reason, we chose to also examine the results on each item, in a exploratory way, in addition to basing ourselves only in the total score of the subscales.

Considering the ordinal nature of the data about socialization goals (scores from one to five), we used the Kruskall Wallis nonparametric tests to compare the responses in each goal among the three types of family, and the nonparametric Spearman correlation to analyze the association between the autonomy, interdependence, and related autonomy scores with the valuation of the ten different socialization goals. All analyses were carried out in the SPSS statistical software for Windows, version 21.

\section{Ethical Considerations}

The project was submitted and approved by the Ethics Committee of PUC-RJ - Protocol (2013-23).

\section{Results and discussion}

Intra and Inter-group comparison of Socialization Goals, Autonomy, Interdependence, and Related Autonomy Scores in Different Types of Family

In the intergrupal comparison, no significant differences were found for the Autonomy $(F(2.47)=2.05 ; p>0.05)$, Interdependence $(F(2.47)=0.37 ; p>0.05)$, and Related Autonomy $\left(x^{2} 2=0.36 ; p>0.05\right)$ scores among the different types of family. As shown in Figure 1, the profiles of autonomy, interdependence, and related autonomy are similar in the different family arrangements. 


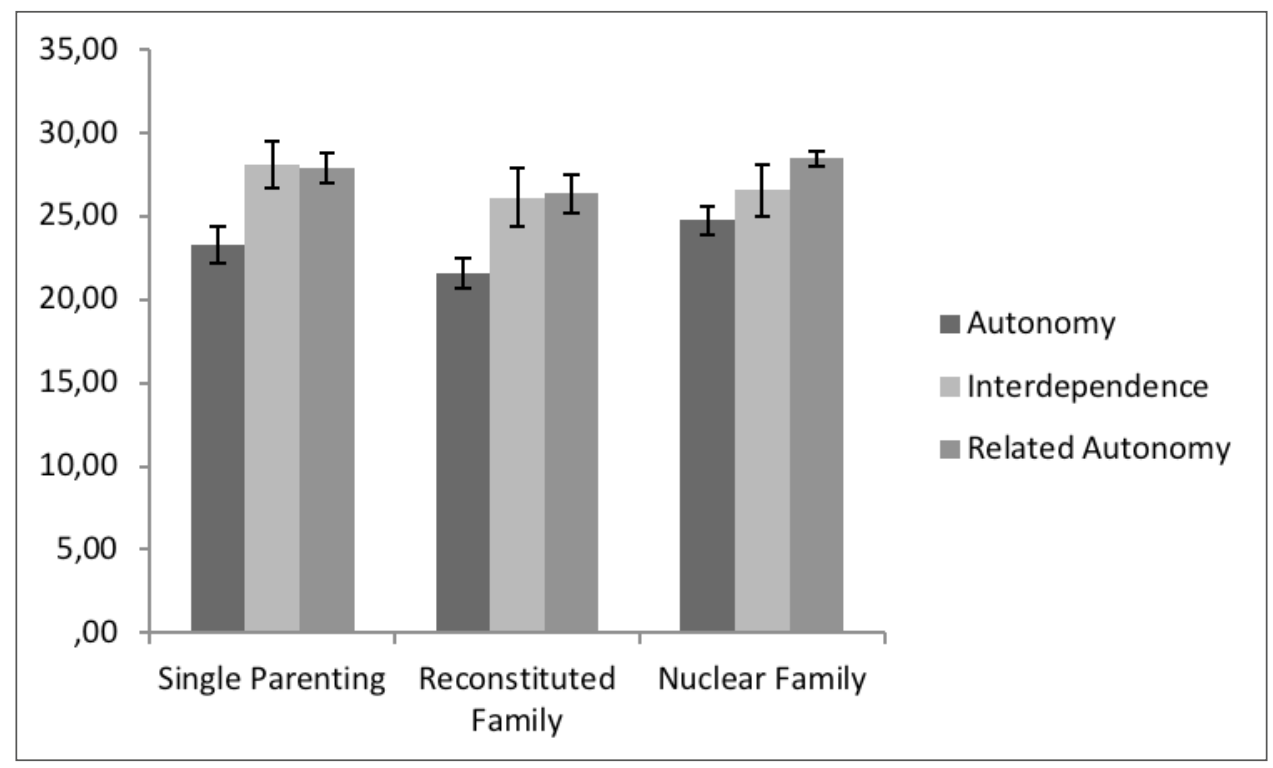

Figure 1. Autonomy, interdependence, and related autonomy scores according to the family arrangement

We observed that for members of these different family arrangements, related autonomy was not significantly higher than interdependence (single-parent families $t(9)=0.16$, $p>0.05$; reconstituted families $t(19)=-0.20, p>0.05$; and nuclear families $t(19)=-1.83, p>0.05)$. However, concerning reconstituted families $(t(18)=3.78, p<0.05)$ and singleparent families $(t(18)=4.56, p<0.05)$, in the comparison among the three scores (autonomy, related autonomy, and interdependence), the higher scores were of interdependence, which differs from findings of previous studies carried out with nuclear families in Rio de Janeiro, which showed the predominance of a autonomous-dependent profile (Seidl-deMoura, Fioravanti-Bastos et al., 2013).

Previous studies, conducted with mothers of young children in family settings of the nuclear type, pointed out to a consistent standard in which related autonomy presented itself as higher than than autonomy and interdependence. The results, so far, showed a clear and consistent profile, which was repeated in studies with various methodologies and in different Brazilian locations (Seidl-de-Moura, Carvalho, \& Vieira, 2013).

Despite the limitation of this study, due to the reduced sample size, and lack of significant inter and intra group differences, we found a trend that differs from the previous standard. This result suggests that the trajectories of autonomy development may not be identical according to family setting, since in a single-parent family, as there is one caregiver, it can be expected that the child develops more interpersonal relationships. In addition, another possible understanding regarding the trajectories of autonomy development in relationships built within a reconstituted family, in which one of the caregivers has a child from a previous relationship in addition to the child from the current marriage, and that may also indicate a greater valuing of interpersonal relationships rather than autonomy.
In the intra-group comparison of autonomy, related autonomy, and interdependence scores among couples of the different family arrangements, we also did not find significant differences between mothers $(N=10)$ and fathers $(N=10)$ of reconstituted families in the autonomy $(t(18)=0.28$, $p>0.05)$, interdependence $(t(18)=-0.11, p>0.05)$, and related autonomy $(t(18)=0.78, p>0.05)$ scores. The same happened in nuclear families. In these families, fathers $(N=10)$ did not differ significantly from mothers $(N=10)$ in their autonomy $(t(18)=-0.98, p>0.05)$, interdependence $(t(18)=-0.13, p>0.05)$, and related autonomy $(t(18)=1,36$, $p>0.05$ ) profiles.

Analyzing separately the scores of mothers and fathers, the standard of greater related autonomy portrayed in previous studies (Seidl-de-Moura, Carvalho et al., 2013) was also not found. Related autonomy was not significantly greater than interdependence for mothers $(t(9)=-1.39$, $p>0.05)$ and parents $(\mathrm{t}(9)=0.59, \mathrm{p}>0.05)$ of reconstituted families. The same happened for mothers of single-parent families $(t(9)=0.16, p>0.05)$. For nuclear families, we did not find a significant difference between the scores of autonomy, interdependence, and related autonomy of mothers or fathers.

Even though the intra and inter-group scores do not present significant differences, it is worth noting the difference in the standard of development trajectories, compared to previous findings. Nevertheless, such a change must be considered according to the different family settings and within a socio-cultural context, since the participants of this study are part of a metropolis with its regional culture and, mostly, come from the middle class.

Regarding the socialization goals, we also did not find significant differences in the means of valuation of goals of interdependence/relationship $(F(2.47)=1.82 ; p>0.05)$ and independence/autonomy $(F(2.47)=1.57 ; p>0.05)$ between 
fathers and mothers of nuclear, reconstituted and singleparent families. The item-by-item analysis revealed that only the valuing of the goal "develop a sense of self-esteem", referring to the autonomy dimension, presents a significant difference between the different family configurations studied $\left(x_{2}^{2}=6.05 ; p<0.05\right)$, with lower scores in reconstituted families than single-parent and nuclear families.

\section{Correlation of autonomy, interdependence, and related autonomy scores of parents with the socialization goals}

The analysis of the correlation between autonomy, interdependence, and related autonomy scores of mothers and fathers with the socialization goals for interdependence/autonomy or independence/autonomy of their children revealed interesting standards. The higher the interdependence scores of fathers and mothers, the higher the valuing of the set of socialization goals for interdependence/relationship ( $\rho=0.46 ; p<0.05)$; and, in the same direction, the higher the related autonomy scores, the higher the valuing of goals focused on independence $(\rho=0.36 ; p<0.05)$. This result indicates a certain consistency degree between the parents' profile and that which they desire for the development of their children concerning autonomy and relationships.

Analyzing item-by-item, positive correlations were found between parents' autonomy score and the valuing of socialization goals 'learn how to cheer up other people' ( $\rho=0.28 ; p<0.05)$ and 'learn to obey older people' ( $\rho=0.34 ; p<0.05)$, which make up the interdependence/ relationship goals subscale. These results were found for the sample as a whole, as well as separately for all family arrangements. This result may indicate that the autonomy degree of mothers and fathers is not associated with or imply a low valuing of the interdependence and relationship goals in the raising of their children, highlighting once again the related autonomy trend of families from Rio de Janeiro found in previous studies.

Analyzing the associations item-by-item from the socialization inventory with the interdependence scores, we found positive correlations with the interdependence/ relationship socialization goals 'learn to obey the parents' $(\rho=0.30 ; p<0.05)$, 'learn to obey older people' $(\rho=0.47$; $p<0.05)$, 'learn how to take care of other people's wellbeing $(\rho=0.40 ; p<0.05)$, 'learn how to cheer up other people' $(\rho=0.33 ; p<0.05)$, and with the goal 'develop competitiveness' $(\rho=0.31 ; p<0.05)$, which is part of the independece/relationship subscale, once more indicating the consistency between the parents' profile and the goals they value, as well as the related autonomous standard of the sample, since the parents' interdependence degree did not imply in low valuing of autonomy goals for the children's development.

Finally, the related autonomy scores, in their turn, were positively correlated with the goals 'develop independence' $(\rho=0.28 ; p<0.05)$, 'develop a sense of self-esteem' $(\rho=0.34 ; p<0.05)$, and 'develop a sense of identity' $(\rho=0.32 ; p<0.05)$, considering the general sample. However, in post hoc analyses, only in reconstituted families it was possible to identify this significant correlation between related autonomy and the goals of developing independence $(\rho=0.53 ; p<0.05)$ and developing a sense of self-esteem $(\rho=0.49 ; p<0.05)$.

Table 1 allows the visualization of such correlations of the autonomy, interdependence, and related autonomy scores of parents with the socialization goals for interdependence/ relationship and independence/autonomy, in its dimensions and for each item separately.

Table 1

Correlation matrix between autonomy, interdependence, and related autonomy scores and development goals

\begin{tabular}{|c|c|c|c|}
\hline & Autonomy & Interdependence & Related Autonomy \\
\hline Interdependent/relationship goals & $.36 *$ & $46^{*}$ & 25 \\
\hline Learn to control emotions & .16 & .06 & .22 \\
\hline Learn to obey the parents & $.25^{\mathrm{R}}$ & $.30 *$ & .03 \\
\hline Learn to obey older people & $.34^{*}$ & $.47 * *$ & .13 \\
\hline Learn how to take care of other people's well-being & .24 & $.40 * *$ & $.25^{\mathrm{R}}$ \\
\hline Learn how to cheer up other people & $.28 *$ & $.33^{*}$ & $.24^{\mathrm{R}}$ \\
\hline Independence/autonomy goals & .05 & .25 & $.36 *$ \\
\hline Develop independence & .02 & .00 & $.28 *$ \\
\hline Develop self-confidence & -.15 & $.25^{\mathrm{R}}$ & .17 \\
\hline Develop a sense of self-esteem & .05 & .18 & $.34^{*}$ \\
\hline Develop competitiveness & .23 & $.31^{*}$ & .12 \\
\hline Develop a sense of identity & .01 & .25 & $.32 *$ \\
\hline
\end{tabular}

Observation: *Significant correlation of $p<005$ in the general sample; **Significant correlation of $p<0.01$ in the general sample; ${ }^{\mathrm{R}}$ Significant correlation only in reconstituted families. 
The results indicate some associations unique to reconstituted families. The positive correlation between the valuing of autonomy on the part of parents and the development of heteronomy goals, such as "learn to obey the parents", suggests that in family arrangements in which there is the presence of non-consanguineous caregivers, there is also a strengthening of the importance of obedience to parents. This association was not found for other family arrangements, which may suggest an increased need to preserve the concepts of hierarchy and respect, even when autonomy is highly valued by the couple. This result corroborates the findings of the study by Ripoll-Núñez et al. (2013), with reconstituted families in Colombia. The authors found in the couples' speech a great valuing of autonomy to make decisions about their children and also a speech of recognition of the importance of respect and obedience to both caretakers, consanguineous or not.

This study sought to analyze possible inter and intragroup differences in the profiles of autonomy, interdependence, and related autonomy of couples in different family arrangements in the city of Rio de Janeiro, as well as to investigate the association of these profiles with the development goals parents have for their children. The analyses showed that the arrangement can be a relevant factor to identify privileged development profiles in familiar contexts.

Concerning socialization goals, regardless of family setting, the dimensions autonomy and dependence, separation, and relationship are present in the interactions mothers/fathers and children in different ways and reflect on the care practices trends of specific development trajectories. The way this dynamic will be offered and its standards will vary according to the context and the family-style adopted.

It is considered that parental goals present themselves as relevant themes to investigations about parenting in different socialization environments, particularly when investigating specific development trajectory trends. Thus, parental goals and expectations can inform what parents want for their children regarding expected developmental acquisitions associated with the preparation of children to express how they feel and what they desire, as well as concerning their development as more autonomous or relational individuals.

We develop relationships, build knowledge, and develop a self in which autonomy and interdependence are differentially valued over our lives and in specific cultural contexts. We stress, therefore, in this study, that in spite of the self being a private matter, it is constituted in relation to the other, through relationships that individuals establishes with their partners, by the beliefs that they acquire regarding the world and the other, taking into consideration the constitution and transmission dynamics in different families.

Despite the small number of participants of each group investigated and application of only two instruments (one to identify the goals and another to identify trajectories), we believe that this study contributed with significant data for the area, encompassing the different family settings and enabling inquiries on the development trajectories undertaken/prioritized by caregivers. It also intends to stimulate new studies on the issues addressed here, especially concerning this necessary association between parental goals and socialization trajectories and the construction of models of self, in different contexts.

\section{References}

Cardoso, A. R. (2011). Avós no século XXI [Grandparents in XXI century]. Curitiba, PR: Juruá.

Carra, C., Lavelli, M., Keller, H., \& Kärtner, J. (2013). Parenting infants: Socialization goals and behaviors of Italian mothers and immigrant mothers from West Africa. Journal of Cross-Cultural Psychology, 44(8), 1304-1320. doi:10.1177/0022022113486004

Citlak, R., Leyendecker, B., Schölmerich, A., Driessen, R., \& Harwood, R.L. (2008). Socialization goals among first-and second-generation migrant Turkish and German mothers. International Journal of Behavioral Development, 32(1), 56-65. doi:10.1177/0165025407084052

Féres-Carneiro, T., \& Magalhães, A. S. (2011). A parentalidade nas múltiplas configurações familiares contemporâneas [Parenthood in multiple contemporary family settings]. In L. V. C. Moreira \& E. P. Rabinovich (Orgs.), Família e parentalidade: Olhares da psicologia e da história [Family and parenting: Looks of psychology and history] (pp. 117-133). Curitiba, PR: Juruá.

Harkness, S., \& Super, C. M. (2006). Themes and variations: Parental ethnotheories in Western cultures. In K. H. Rubin \& O. B. Chung (Eds.), Parenting beliefs, behaviors, and parent-child relations: A cross-cultural perspective (pp. 61-79). New York, NY: Psychology Press.

Kağitçibaşi,Ç.(2012). Socio-culturalchangeandintegrative syntheses in human development: Autonomousrelated self and social-cognitive competence. Child Development Perspectives, 6(1), 5-11. doi:10.1111/j.1750-8606.2011.00173.x

Keller, H. (2007). Cultures of infancy. Mahwah, NJ: Lawrence Erlbaum.

Keller, H. (2012). Autonomy and relatedness revisited: Cultural manifestations of universal human needs. Child Development Perspectives, 6(1), 12-18. doi:10.1111/j.1750-8606.2011.00208.x

Keller, H., Lamm, B., Abels, M., Relindis, Y., Borke, J., Henning, J., ... Chaudhary, N. (2006). Cultural models, socialization goals and parenting ethnotheories: A multicultural analysis. Journal of Cross-Cultural Psychology, 37(2), 155-172. doi:10.1177/0022022105284494

Kobarg, A. P. R., Sachetti, V. A. R., \& Vieira, M. L. (2006). Valores e crenças parentais: Reflexões teóricas [Values and believes parental: Theoretical considerations]. Revista Brasileira do Desenvolvimento Humano, 16(2), 96-102. Retrieved from http://pepsic.bvsalud.org/scielo. php?script $=$ sci_arttext\&pid $=$ S0104-12822006000200010 
Lamm, B., \& Keller, H. (2007). Understanding cultural models of parenting: The role of intracultural variation and response style. Journal of Cross-Cultural Psychology, 38(1), 50-57.

Lordelo, E. R., Roethle, M., \& Mochizuki, A. B. (2012). Metas de socialização em diferentes contextos [Socialization goals in different contexts]. Paidéia (Ribeirão Preto), 22(51), 33-42. doi:10.1590/S0103-863X2012000100005

Martins, G. D. F., Macarini, S. M., Vieira, M. L., Seidl-deMoura, M. L., Bussab, V. L. R., \& Cruz, R. M. (2010). Construção e validação da Escala de Crenças Parentais e Práticas de Cuidado (E-CPPC) na primeira infância [Construction and validation of the parenting beliefs and caring practices scale for the early childhood]. Psico-USF, 15(1), 23-34. doi:10.1590/S1413-82712010000100004

Mead, M. (1963). Socialization and enculturation. Current Anthropology, 4(2), 184-207.

Miller,A.M.,\&Harwood,R.L.(2001).Long-termsocialisation goals and the construction of infants' social networks among middle class Anglo and Puerto Rican mothers. International Journal of Behavioral Development, 25(5), 450-457. doi:10.1080/016502501316934888

Park, H., Coello, J.A., \& Lau, A. S. (2014). Child socialization goals in East Asian versus Western nations from 1989 to 2010: Evidence for social change in parenting. Parenting, 14(2), 69-91. doi:10.1080/15295192.2014.914345

Ripoll-Núñez, K., Martínez Arrieta, K., \& Giraldo Gallo, A. M. (2013). Decisiones sobre crianza de los hijos en familias reconstituídas [Decisions about parenting in stepfamilies]. Revista Colombiana de Psicología, 22(1), 163-177. Retrieved from https://revistas.unal.edu.co/ index.php/psicologia/article/view/20781/43291

Seidl-de-Moura, M. L. (2012). Introduction. In M. L. Seidl-de-Moura (Ed.), Human development: Different perspectives (pp. 3-18). London, United Kingdom: InTechOpen.

Seidl-de-Moura, M. L., Carvalho, R. V. C. C., \& Vieira, M. L. (2013). Brazilian mothers parenting models. In M. L. Seidlde-Moura (Ed.), Parenting in South American and African contexts (pp. 1-15). London, United Kingdom: InTechOpen.

Seidl-de-Moura, M. L., Bandeira, T. T. A., Campos K. N., Cruz, E. M., Amaral, G. S., \& Marca, R. (2009). Parenting cultural models of a group of mothers from Rio de Janeiro. Spanish Journal of Psychology, 12(2), 506-517. doi:10.1017/S1138741600001888

Seidl-de-Moura, M. L., Fioravanti-Bastos, A. C., Carvalho, R. V.C.,\&Ziviani,C.(2013).Adaptaçãobrasileira das escalas de self autônomo, relacionado e autônomo-relacionado de Ç. Kağitçibaşi [Brazilian adaptation of Ç. Kağitçibaşi's Scales of Autonomous, Related and Related-autonomous Self]. Avaliação Psicológica, 12(2), 193-201. Retrieved from http://pepsic.bvsalud.org/scielo.php?script=sci arttext\&pid=S1677-04712013000200010
Suizzo, M.-A. (2002). French parents' cultural models and childrearing beliefs. International Journal of Behavioral Development, 26(4), 297-307. doi:10.1080/01650250143000175

Whiting, B. (Ed.). (1963). Six cultures: Studies of child rearing. New York: Wiley.

Vieira, M. L., Seidl-de-Moura, M. L., Macarini, S. M., Martins, G. D. F., Lordelo, E. R., Tokumaru, R. S., \& Oliva D. O. (2010). Autonomy and interdependency: Beliefs of Brazilian mothers from State capitals and small towns. Spanish Journal of Psychology, 13(2), 818826. doi:10.1017/S113874160000247X

Luciana Fontes Pessôa is a Professor of the Pontifícia Universidade Católica do Rio de Janeiro, Rio de Janeiro-RJ, Brazil.

Dandara Ramos is a postdoctoral research fellow at the Fiocruz Bahia, Salvador-BA, Brazil.

Lenise Vivas is a Psychology undergraduate at the Pontifícia Universidade Católica do Rio de Janeiro, Rio de Janeiro-RJ, Brazil.

\section{Authors' Contribution:}

All authors made substantial contributions to the conception and design of this study, to data analysis and interpretation, and to the manuscript revision and approval of the final version. All the authors assume public responsibility for content of the manuscript.

Received: Jun. 13, 2016

1st Revision: Oct. 13, 2016

2nd Revision: May. 05, 2017

Approved: Apr. 12, 2018

How to cite this article:

Pessôa, L. F., Ramos, D., \& Vivas, L. (2019). Profiles and developmental goals in different families of Rio de Janeiro. Paidéia (Ribeirão Preto), 29, e2906. doi: http://dx.doi.org/10.1590/1982-4327e2906 